\title{
A Fuzzy Based Comprehensive Study of Factors Affecting Teacher's Performance in Higher Technical Education
}

\author{
Sunish Kumar O S \\ Asst. Professor, Dept. of Electronics and Communication Engineering, Amaljyothi College of Engineering \\ Email: ossunishkumar@amaljyothi.ac.in
}

\begin{abstract}
The main objective of this paper is to suggest a model for improving and retaining the highly qualified teachers in higher technical education. There are numerous researches going on all over the world regarding the key quality factors which are directly linked with teacher's performance and the methods to improve them. Whatever the methods and measures, the teacher's active participation and dedication is very important to achieve these objectives. A detailed questionnaire was distributed to highly qualified and experienced teachers who are working in engineering colleges for more than five years. Since the variables in this study are quality factors, the collected data is analyzed using the fuzzy logic and inference is drawn for getting more accurate results compared to probability study of the same case. Based on the results obtained from fuzzy inference system, a new model called Adaptive Performance-Incentive-Development (PID) control system for improving the quality as well as retaining the highly qualified teachers in the teaching profession is created.
\end{abstract}

Index Terms - Fuzzy Logic, Teacher's Performance, Incentive System, MATLAB

\section{INTRODUCTION}

The quality and performance of teachers have always been a focus of concern for most of the educational researchers. The quality of teaching is not only governed by the qualification, knowledge and skills but also their enthusiasm, dedication and commitment in teaching. We can easily develop a bundle of measures to improve all the quality factors like personal abilities, teachinglearning process, research culture etc. But developing other factors like enthusiasm, dedication and commitment in teaching is a herculean task. The retention of the highly qualified teachers in teaching profession is another difficult thing these days. In most of the countries, specifically in low income countries (LIC) a huge amount of well qualified teachers left the teaching profession and joined software jobs and other government jobs. The main reason for this situation is the inability of current compensation system for the teachers in such countries. So in order to tackle with such a situation a well systematic compensation system has to be introduced. In most of the countries, there is a notable mismatch between the salaries of teachers and other professionals having the same qualifications. The Article 115 of the 1966 ILO/UNESCO recommendation concerning the status of teacher's states that 'teacher's salary should compare favorably with salaries paid in other occupations requiring similar or equivalent qualifications'. This factor eventually leads to the absenteeism and decline in the number of people interested in teaching profession. In some perspective especially in designing the compensation system and fixing of salaries, we should consider teacher like a real worker of an organization and all the benefits of the workers like incentives, over time allowance etc should be given. So in the proposed model of this paper the teachers are named as 'knowledge workers' because teachers are really working with their knowledge and frequently they have to upgrade it. So the share of enthusiasm, dedication, commitment, retention etc can be improved by motivating them by giving rewards, good work environment, freedom in selecting teaching methods, job security etc. But the remaining can be improved only by giving the additional monetary benefits. So a performance based incentive system has to be implemented. So this paper suggests an adaptive system which adaptively changes the incentives based on the error difference between the actual performance and the desired performance obtained from the feedback. Thus the teacher's qualities are developed through an adaptive incentive system based on performance, so has the name 'Adaptive Performance-IncentiveDevelopment (PID) control system'.

This paper is organized in the following manner. The section II discusses some of the main contents of the papers obtained from the literature review. The section III discusses the objectives and various limitations of the study. The section IV discusses the key techniques used in this study. The section $\mathrm{V}$ discusses the data analysis and interpretations of the study. The section VI discusses the proposed model. The section VII concludes the paper. 


\section{THE LITERATURE REVIEW}

There are many researches carried out all over the world in order to study the key quality factors which affect teacher's performance. But we can see only few studies which deal with the compensation and incentives system for teachers in order to retain them in the teaching profession. Dr. Anil Kumar Professor, Measurement and Evaluation NITTTR [1], tells in his study on ensuring teacher's accountability through performance evaluation that all policy statements on the higher and technical educational system in India refer to its importance in terms of its role in providing crucial inputs to socio-economic development through creation and dissemination of knowledge and skills as also "being the ultimate guarantee of national self-reliance". Every time there is a Pay Commission or Committee, it invariably tries to award the enhanced salary with certain terms and conditions. The recent commission is also no exception. This is done with an intention to ensure better qualitative changes in the higher and technical education scenario. But the irony of the situation is that revised scales of pay are implemented without much discussion on the need for Quality Assurances and the accountability of the teachers. As a result teaching profession is left without any meaningful evaluation and the concept of accountability has completely disappeared into the thin air not leaving behind even a faint fragrance. Katharina Michaelowa [2] states that low teacher motivation and its detrimental effect on student achievement are central problems of many education systems in Africa. It appears that there is only very limited evidence of the effectiveness of intensively debated and costly measures such as increasing teachers salaries, reducing class size, and increasing academic qualification requirements. It also appears that teacher job satisfaction and education quality are not necessarily complementary objectives. Peter Dolton , Andrew Tremayne and Tsung-Ping Chung [3], a paper commissioned by the Education and Training Policy Division, OECD, for the Activity Attracting, Developing and Retaining Effective Teachers tells that the overall objective of the Attracting, Developing and Retaining Effective Teachers Activity is to provide policy makers with information and analysis to assist them in formulating and implementing teacher policies leading to quality teaching and learning at the school level. The activity is intended to: (i) synthesize research on issues related to policies concerned with attracting, recruiting, retaining and developing effective teachers; (ii) identify innovative and successful policy initiatives and practices; (iii) facilitate exchanges of lessons and experiences among countries; and (iv) identify policy options. It begins by defining and measuring the business cycle in the UK. This paper examines how the economic cycle affects the market for teachers. Paul Bennell[4], in his paper titled Teacher Motivation and Incentives in sub-saharan Africa and Asia, tells that teacher motivation and incentives in lowincome developing countries (LICs) in sub-Saharan Africa and Asia depend on the extent to which the material and psychological needs of teachers are being met. This includes overall levels of occupational status, job satisfaction, pay and benefits, recruitment and deployment, attrition, and absenteeism. Unfortunately, despite the importance and complexity of these issues, there is very limited good quality published information. Teachers in most LICs are 'semiprofessionals' mainly because of their relatively low levels of education and training vis-à-vis professional occupations such as doctors, engineers and lawyers; Also, the sheer size of the teaching force militates against 'professional' exclusivity. Teaching has become 'employment of the last resort' among university graduates and secondary school leavers in many countries. Consequently, teachers often lack a strong, long-term commitment to teaching as a vocation. Pedro S. Martins [5], answers the query "How teacher incentives affect student achievement?" by examining the effects of the recent introduction of teacher performance-related pay and tournaments in Portugal's public schools. Specifically, he worked on matched student school panel data covering the population of secondary school national exams over seven years. He then conducted a differencein-differences analysis based on two complementary control groups: public schools in two autonomous regions that were exposed to lighter versions of the reform than in the rest of the country; and private schools, which are also subject to the same national exams but whose teachers were not affected by the reform. His results consistently indicate that the increased focus on individual teacher performance caused a significant decline in student achievement, particularly in terms of national exams. The triple difference results also document a significant increase in grade inflation.

\section{OBJECTIVES AND LIMITATIONS OF THE STUDY}

The objectives and limitations of the study are explained in this session.

\section{A. Objectives}

The quality and performance of teachers have always been a focus of concerns in education and teacher education research. The quality of teaching is not only governed by the qualification, knowledge and skill competence of teachers but also their enthusiasm, dedication and commitment in teaching. When a teacher is motivated and loves the teaching profession, the students not only learn the content taught by the teacher, but the students are also motivated toward learning. Teachers who are dedicated to teach would facilitate the innovations or reformations that are meant to be beneficial to students' learning and development. The problems of recruitment and retention of good teacher's especially in higher technical education have been repeatedly reported in different countries. From the above discussion it is clear that a quantitative and a qualitative study of the factors affecting teacher's 
performance is vital and such study will identify the strengths and weaknesses of a teacher from the perspective of an organization and teacher's community. So the objective of this study is to explore the relation between some of the qualitative factors like Personal Abilities, Teaching Learning Process, Responsibility and Punctuality, Student Management, Professional Ethics, Research and Publications and some of the external factors like Training and Development, Job Security and status, Compensation and Incentives and General Factors with the teacher's performance.

\section{B. Limitations}

Although there are good numbers of objectives yet there are some limitations also. They are,

1. Only limited number of qualified and experienced employees were available during the study.

2. The other limitation was that the respondents were not in the same age group. Majority was in between 25 and 35 and remaining was above 50.

3. There were a limited number of professors available for the survey and majority consisted of assistant professors.

\section{THE KEY TECHNIQUES USED}

This session will explain the key techniques used for the sample collection, data analysis and interpretations.

\section{A. Selection of samples}

In this study the stratified random sampling method is used. Stratified random sampling is a technique which attempts to restrict the possible samples to those which are 'less extreme' by ensuring that all parts of the population are represented in the sample in order to increase the efficiency (that is to decrease the error in the estimation). In stratified sampling, the population of ' $\mathrm{N}$ ' units is first divided into disjoint groups of $\mathrm{N}_{1}, \mathrm{~N} 2, \ldots$, $\mathrm{Nh}, . . \mathrm{NL}$, units, respectively. These subgroups called strata, together compromise the whole population, so that $\mathrm{N}_{1}+\mathrm{N}_{2}+\ldots \mathrm{N}_{L}=\mathrm{N}$. The strata here can be treated as a group of teachers working in same department. From each stratum a sample of pre-specified size is drawn independently in different strata. Then the collection of these samples constitutes a stratified sample. Since a simple random sample selection scheme is used in each stratum, the corresponding sample is called a stratified random sample.

\section{B. The Fuzzy Logic}

So far as the laws of mathematics refer to reality, they are not certain. And so far as they are certain, they do not refer to reality."

\section{- Abert Einstein}

The above sentence is a famous quote given by the great scientist Albert Einstein. In some practical situations, the probabilistic study does not give the accurate results. So we have to adopt a new technique which closely approximates the reality. One such technique is the Fuzzy Logic. Fuzzy set theory, the bedrock of fuzzy logic, was introduced by Lofti Zadeh in 1965. It was specifically designed to mathematically represent uncertainty and vagueness with formalized logical tools for dealing with the imprecision inherent in many real-world problems [8]. Zadeh observed that most of the concepts with which humans wrestle and label experience are imprecise or "fuzzy." This is both a necessity and an advantage. For example, consider comparatively simple labels, such as tall and very tall. There is no precise boundary between these two labels; people do not carry around in their heads numeric values to distinguish the concept very tall from tall. These are what Zadeh (1973) identified as fuzzy variables because of their gradual progression from membership to nonmembership in a fuzzy set.

Thus, the central notion of fuzzy logic is that "truth values" or "membership values" can vary continuously from, by convention, 0 to 1 . In contrast, when bivalent logic is used, there are only two possible "truth values": 0 (false) and 1 (true). With this foundation laid, we can briefly cover some other important characteristics of fuzzy logic as outlined by Zadeh. In fuzzy logic,

- Exact reasoning is viewed as a limiting case of approximate reasoning.

- $\quad$ Everything is a matter of degree.

- Knowledge is interpreted as a collection of elastic, fuzzy constraints on a collection of variables.

- Inference is viewed as a process of propagation of elastic constraints.

- Any logical system can be "fuzzified."

The conceptual model of the various components of a traditional fuzzy system is shown in Figure 1.

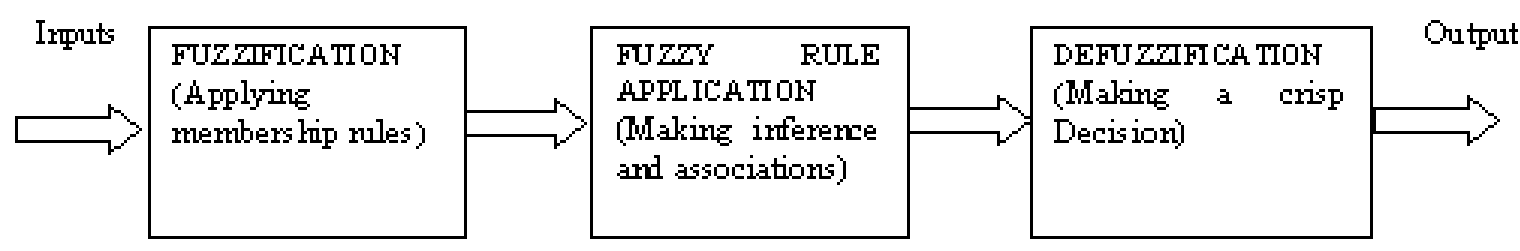

Fig. 1: lock Diagram of a Fuzzy System 
The first step is to fuzzyfy the input. This basically means applying fuzzy membership functions to the input - assigning group memberships and membership values to input data. The second step is to use Zadeh's fuzzy set logic combined with knowledge about the system to make a set of inferences and associations between and among members in various groups.

The last step is to "defuzzify" these inferences and associations and reach a crisp decision or create some crisp output for the system. It is used in many different ways in many different arenas. Most of its applications to date have little to do with psychology: creation of machine intelligence and expert systems, complex machine control systems, robotics, computer processor design, man-machine interfacing, weather system modeling, and endless uses in consumer products.

\section{The Fuzzy Inference System (FIS) in MATLAB}

MATLAB [7] is a high performance language for technical computing. It integrates computation, visualization and programming in an easy-to-use environment where problems and solutions are expressed in familiar mathematical notation.

Fuzzy inference is the process of formulating the mapping from a given input to an output using fuzzy logic. The mapping then provides a basis from which decisions can be made, or patterns discerned. We can implement two types of fuzzy inference systems in the fuzzy toolbox: Mamdani-type and Sugeno-type. These two types of inference systems vary in the way outputs are determined. We use the Mamdani- type inference system in this study. This will give a fuzzy variable itself as the output and finally it is defuzzified in order to get a crisp value.

Mamdani's fuzzy inference method is the most commonly seen fuzzy methodology. Mamdani's method was among the first control systems built using fuzzy set theory. It was proposed in 1975 by Ebrahim Mamdani as an attempt to control a steam engine and boiler combination by synthesizing a set of linguistic control rules obtained from experienced human operators. Mamdani's effort was based on Lotfi Zadeh's 1973[9] paper on fuzzy algorithms for complex systems and decision processes.

Mamdani-type inference, as defined for the toolbox, expects the output membership functions to be fuzzy sets. After the aggregation process, there is a fuzzy set for each output variable that needs defuzzification. It is possible, and in many cases much more efficient, to use a single spike as the output membership function rather than a distributed fuzzy set. This type of output is known as a singleton output membership function, and it can be thought of as a pre-defuzzified fuzzy set. It enhances the efficiency of the defuzzification process because it greatly simplifies the computation required by the more general Mamdani method, which finds the centroid of a two-dimensional function. Rather than integrating across the two-dimensional function to find the centroid, we use the weighted average of a few data points. Sugenotype systems too support this type of model. In general, Sugeno-type systems can be used to model any inference system in which the output membership functions are either linear or constant.

Thus the Fuzzy inference process comprises of five parts: fuzzification of the input variables, application of the fuzzy operator (AND or OR) in the antecedent, implication from the antecedent to the consequent, aggregation of the consequents across the rules, and defuzzification.

\section{DATA ANALYSIS AND INTERPRETATION}

The data analysis and interpretation is given in this session. A total of fifty detailed questionnaires were distributed to randomly selected samples from each strata and their agreement with each item is collected. A five point Linkert scale is used in this study with the scales ranging from 'critically affects' to 'do not affect' the teacher's performance. The detail of the questionnaire (Secondary) data collection is given in the following table.

Table 1: Status of the response

\begin{tabular}{|c|c|c|c|}
\hline No. & IT EM & RESPONSE & $\%$ RE SPONSE \\
\hline 1. & Resporse to the questionnaire & 35 & $70 \%$ \\
\hline 2. & Number of male responder & 17 & $48.57 \%$ \\
\hline 3. & Nurber of female responders & 18 & $51.4 \%$ \\
\hline 4. & Nunber of Asst. Professors & 31 & $88.57 \%$ \\
\hline 5. & Humber of Professor & 4 & $11.42 \%$ \\
\hline
\end{tabular}


The results obtained from the Fuzzy Analysis of the collected data are given in the following table. The table includes variables, score obtained from general opinion, score obtained from self assessment and the degree of membership for these variables with the fuzzy set 'Teacher's Performance'.

Table 2: Summary of the fuzzy based inference

Fuzy Inference Type: Mamdani Type

\begin{tabular}{|c|c|c|c|c|}
\hline No. & Variables & $\begin{array}{l}\text { Score obtained } \\
\text { from general } \\
\text { openion }\end{array}$ & $\begin{array}{l}\text { Score ob tained } \\
\text { from Self } \\
\text { Assessment }\end{array}$ & $\begin{array}{c}\begin{array}{c}\text { Degree of } \\
\text { membershi }\end{array} \\
\text { [0 1] }\end{array}$ \\
\hline 1. & Personal Abilities & 170.9 & 160.5 & 0.73 \\
\hline 2. & $\begin{array}{c}\text { Teaching Learning } \\
\text { Process }\end{array}$ & 193.3 & 179 & 0.716 \\
\hline 3. & $\begin{array}{l}\text { Resposibility and } \\
\text { Punctuality }\end{array}$ & 797 & 769 & 0.695 \\
\hline 4. & Student Maragement & 826 & 82 & 0.68 \\
\hline 5. & Professional Ethics & 886 & 834 & 0.69 \\
\hline 6. & $\begin{array}{l}\text { Research and } \\
\text { publication }\end{array}$ & 1549 & 1408 & 0.713 \\
\hline 7. & $\begin{array}{l}\text { Compensation and } \\
\text { incentives }\end{array}$ & 427 & - & 0.902 \\
\hline 8. & $\begin{array}{l}\text { Training and } \\
\text { development }\end{array}$ & 579 & - & 0.902 \\
\hline 9. & Job security \& status & 125.5 & - & 0.90 \\
\hline 10. & General Factors & 828 & - & 0.502 \\
\hline
\end{tabular}

For the truthfulness of the collected data, we are assuming that the respondents are well qualified and therefore, a self opinion is also taken. As evident from the Table 2 it is clear that in the fuzzy based analysis for finding the key factors affecting teacher's performance, the compensation and incentive, Training and development and Job security and status have got the higher degrees of membership in the fuzzy set 'Factors Affecting Teacher's Performance' with the membership values $0.902,0.902$ and 0.90 respectively. The Paper titled "TEACHER MOTIVATION AND INCENTIVES IN SUB-SAHARAN AFRICA AND ASIA" by Paul Bennell [4], supports this study.

\section{THE PROPOSED MODEL}

Based on the study and results obtained from the study, a new model for improving and retaining teachers in the teaching profession is given in this session. From the general study using the fuzzy logic it is clear that the compensation and the incentives, training and development and job security and status have got higher membership value because all are uniquely agreeing with these factors. So in this study, the proposal based on the study is based on the importance of incentive system and compensation based on the performance. The proposed model is given in the following figure.

It is a performance based incentive system for the development of the knowledge workers. Here the knowledge worker is teacher because they work with their knowledge. So like any other job, this job is also well reputed and a highly skilled job. So there is need for implementing reasonable compensation and performance based incentive system. The mentioned feedback control system is adaptive in which the compensator block will adaptively change the incentives based on the performance. 


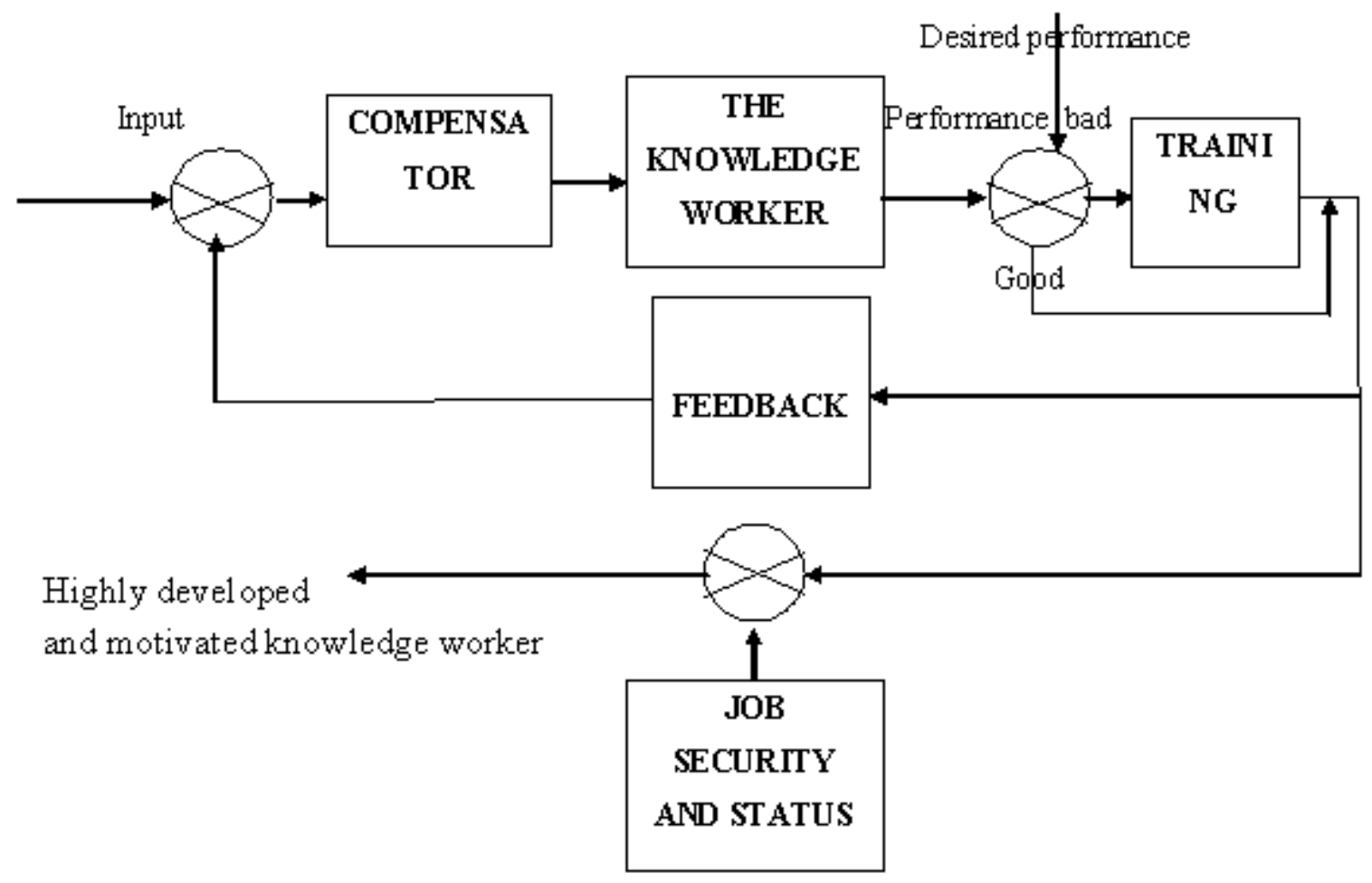

Fig.2: Adaptive Performance-Incentive- Development (PID) control system

The above proposed model is a Feedback based PID controller system where $\mathrm{P}, \mathrm{I}$ and $\mathrm{D}$ respectively imply Performance, Incentives and Development.

The FEEDBACK block is the feedback taken by the organization and it is compared with the desired performance. Then the performance measure is given to an adder/Substractor (circular block). The output is error value obtained by comparing the input and the perceived performance and then it is given to the COMPENSATOR block. This block will reduce this error value by adaptively changing the incentives and given to the KNOWLEDGE WORKER. The result is improved performance. The output performance is compared with the desired performance and if it bad then a training is given and if it is good then it is bypassed to FEEDBACK.

\section{A. The Individual Development Plan (IDP)}

All the teachers should develop an Individual Development Plan (IDP) at the beginning of every academic year. This is a comprehensive report of the individual action plans for the coming academic year. This should include the details of individual activities in the areas like Improving Personal Abilities, Teaching Learning Processes, Responsibility and Punctuality, Student Management, Research and publication, Contributions to the College and Society, Extracurricular activities etc. This proposed report prepared by every teacher should be submitted to the evaluating authority. At the time of the performance evaluation, this report can be considered as the desired performance of the teacher. During the evaluation the evaluator will closely correlate this desired performance and the perceived performance and decisions are made. If the performance is good then a suitable incentive is given, otherwise they will undergo training for improving their weak areas as proposed by our model.

\section{B. $360^{\circ}$ Feedback System}

Another important thing is the feedback system. In most of the educational institutions, more than 50\% feedback marks are from the student evaluation alone. There may be some negative individual bias between the teacher and some of the students. This will be reflected badly in the feedback and eventually it may demotivate the teachers. Another important thing is the consideration for the toughness of the subject. Special consideration should be given to the teachers who are handling the tough subjects. So an effective feedback system suggested in this study is the $360^{\circ}$ feedback system. The 360 -Degree feedback is a performance appraisal tool, which includes feedback from superiors, peers, subordinates, students and self appraisal. Traditional feedback process is one- degree type evaluation system usually the immediate superior conducting the feedback. On the other hand, by involving more than one person, the 360- Degree feedback makes the appraisal process more meaningful for both the parties. A proposed marks division for the feedback is depicted in table 3

\section{CONCLUSION}

A quantitative and qualitative study was conducted for analyzing the factors affecting teacher's performance in higher technical education. The Fuzzy Logic method 
is used for the inference of the study and the fuzzy inference type used is Mamdani type. From the inference drawn by the fuzzy analysis, it is clear that the factors that having the highest degree of membership with the teachers performance are Compensation and Incentives, Training and Development and Job security and status. Based on this result, an efficient model for the performance improvement and retention is proposed and the model is an 'Adaptive Performance-IncentiveDevelopment (IDP) control system. And also a $360^{\circ}$ feedback system is proposed for the efficient performance evaluation.

Table 3: The proposed marks division for feedback

\begin{tabular}{|c|c|c|}
\hline No. & ITEMS & PROPOSED \% MARKS FOR FEEDBACK \\
\hline 1. & Individual Development Plan (IDP) & $30 \%$ \\
\hline 2. & Superiors & $20 \%$ \\
\hline 3. & Peers & $10 \%$ \\
\hline 4. & Subordinates & $10 \%$ \\
\hline 5. & Students & $20 \%$ \\
\hline 6. & Self Appraisal & $10 \%$ \\
\hline 7. & Total & $100 \%$ \\
\hline
\end{tabular}

\section{REFERENCES}

[1] 'ENSURING TEACHERS' ACCOUNTABILITY THROUGH PERFORMANCE EVALUATION" by Dr. Anil Kumar Professor, Measurement and Evaluation NITTTR, Bhopal

[2] “TEACHER JOB SATISFACTION, STUDENT ACHIEVEMENT, AND THE COST OF PRIMARY EDUCATION IN FRANCOPHONE SUB-SAHARAN AFRICA" by Katharina Michaelowa. HWWA DISCUSSION PAPER 188 Hamburgisches Welt-Wirtschafts-Archiv (HWWA) Hamburg Institute of International Economics 2002 ISSN 1616-4814r.

[3] "THE ECONOMIC CYCLE AND TEACHER SUPPLY" by Peter Dolton, Andrew Tremayne and Tsung-Ping Chung, a paper commissioned by the Education and Training Policy Division, OECD, University of Newcastle-upon-Tyne and Centre for Economic Performance, London School of Economics, March 2003

[4] "TEACHER MOTIVATION AND INCENTIVES IN SUB-SAHARAN AFRICA AND ASIA" by Paul Bennell, Knowledge and Skills for Development, Brighton, July 2004

[5] "INDIVIDUAL TEACHER INCENTIVES, STUDENT ACHIEVEMENT AND GRADE INFLATION" by Pedro S. Martins, Queen Mary, University of London, CEG-IST and IZA Discussion Paper No. 4051 March 2009

[6] FUZZY LOGIC WITH ENGINEERING APPLICATIOS by TIMOTHY J ROSS, University of New Mexico, USA, Second edition, WILEY Publications
[7] GETTING STARTED WITH MATLAB, The Mathworks, Inc., 3 Apple Hill Drive, Natick, MA 01760-2098

[8] ZADEH, L. (1965) Department of Electrical Engineering and Electronics Research Laboratory, University of California, Berkeley, California, USA. Fuzzy sets. Information and Control, 8, 338353.

[9] LOTFI ZADEH 1973, paper on fuzzy algorithms for complex systems and decision processes. IEEE Transactions, Man and Cybbernetics,3,28-44

\section{AUTHOR'S PROFILES}

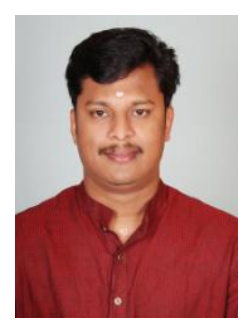

Sunish Kumar O S: Mr. Sunish Kumar is currently working as Asst. Professor in an Engineering college at Kerala. He did $\mathrm{B}$ Tech in Electronics and Communication Engineering from Cochin University of Science and Technology and MBA in HRM \&FINANCE from Kerala University, Trivandrum and now he is pursuing $M$ Tech in Optoelectronics and Communication Systems in CUSAT. Mr. Sunish has authored several papers in National and International Conferences and International Journals. His interested areas are Communication Systems, Digital Signal Processing, Applications of Fuzzy logic in Management, Optical Burst Switched Networks etc. Mr. Sunish Kumar is a recipient of Baba Sahib Dr. Ambedkar National Fellowship Award 2011 for his contributions to the field of education and cultural activities. 